\title{
Fiscal, Monetary, and Financial Interactions in Dynamic General Equilibrium
}

\author{
Holger Strulik \\ University of Hannover \\ Leibniz Universität Hannover, Discussion Paper No. 402 \\ ISSN 0949-9962
}

June 2008

This paper proposes a model that links households and firms, as usual, by markets for factors and goods and, additionally, by a banking sector that channels households' funds to firms and eliminates idiosyncratic risk. In equilibrium, agency costs and tax benefits of corporate debt are equalizing each other, which renders an institutionally based explanation of financial structure. Adjustment of corporate finance adds to the ordinary savings channel of fiscal and monetary policy. Taking real and financial interactions into account, the model predicts a somewhat lower impact of fiscal policy on macroeconomic aggregates as commonly assessed and a much stronger impact of monetary policy. This amplification is caused by the banking sector's translation of borrowing rates into lending rates and vice versa.

Keywords: Fiscal Policy, Monetary Policy, Corporate Finance, Agency Costs, Banking, Economic Growth, Business Cycles.

JEL Classification: E44, E52, E62, O16. 


\section{INTRODUCTION}

That fiscal and monetary policy affect the real economy through their impact on households' allocation of assets and time is common knowledge in modern macroeconomics. This so called savings channel (or interest rate channel) is investigated in quantitative growth theory in order to estimate the welfare gain from policy reform and in business cycle theory in order to assess the propagation and amplification of shocks (see, among many others, Cooley and Hansen, 1989, 1992).

A by now quite large literature argues that on top of the saving channel there exists another mechanism, the so called credit (or lending) channel, through which policy matters for real economic performance. With contrast to the savings channel, which is based on household behavior, the argument originates now from the firm side of the economy. In the short run, firms are equityconstraint and contract with banks (or, generally, financial intermediaries) in order to finance their input bill. If monetary or fiscal policy has the power to affect the desired financial structure or the terms of the contract, it will have real consequences through the size of the projects run by firms and the entailed costs, i.e. through factor demand and factor costs. Since this mechanism operates additionally to the savings channel, it has become known as the financial accelerator (Bernanke and Gertler, 1995).

Interestingly, monetary economics and public economics have developed different views on the modelling of the credit channel. One purpose of the present paper is to integrate both views into a unifying framework.

Monetary economics, originating from the real business paradigm, focusses on the cost aspects of the credit channel. For that purpose it has integrated into dynamic general equilibrium a microfoundation of how firms, suffering from idiosyncratic risk, contract with banks. The resulting agency costs constrain the demand of debt and determine optimal financial structure (see among many others, Bernanke and Gertler, 1989, Carlstrom and Fuerst, 1997, 2001). The problem of this approach is that the costs of debt are nowhere counterbalanced by inherent benefits of debt. In a dynamic setting, i.e. with the possibility to accumulate capital, one would thus expect firms to be completely equity-financed in the long-run. In order to circumvent this problem the literature assumes that firms are led by entrepreneurs that are different from other households (the ultimate

*Correspondence: University of Hannover, Wirtschaftswissenschaftliche Fakultät, Königsworther Platz 1,30167 Hannover, Germany; email: strulik@vwl.uni-hannover.de. 
suppliers of credit). Entrepreneurs are assumed to have either a shorter life or a higher rate of time preference than their fellow men. The modelling could thus be characterized as a behavioral foundation of the credit channel.

Public economics emphasizes the benefit aspects of the credit channel. Firms are modelled as corporations and the different tax treatment of corporate income and private capital income creates a tax advantage of debt (See among many others Auerbach, 2002, Turnovsky, 1990, Strulik, 2003). While the introduction of a corporate sector allows to go without separating households into groups of different life length or time preference, the modelling lacks the sophisticated microfoundation of agency costs. In fact, without further restrictions one would expect from the public economics approach that corporations are completely debt-financed in the long-run. In order to avoid this problem, the literature introduces either exogenous upper limits for the debt ratio or restricts firm behavior by exogenous functions for the costs of debt.

Combining the micro-foundation of agency cost from monetary economics with the tax benefit approach from public economics the present model proposes an institutional foundation of the credit channel. Financial structure is determined by the design of the tax system and the banking system. Some elements of these ideas are already present in Strulik (2008). This first approach, however, failed to model the banking sector explicitly and monetary policy was not investigated. Here, I extend the model by a banking sector, similar to the one proposed by Diaz-Gimenez et al. (1992), and by investigating the long-run and short-run responses to monetary policy.

The paper can also be conceptualized as a an advancement of Carlstrom and Fuerst's (2001) article. Their model is modified by replacing the behavioral foundation of the credit channel by an institutional one, i.e. by introducing a corporate sector, a public sector, and a tax advantage of debt. It is extended by an explicitly modelled banking sector, which costly transforms deposits to loans.

The next section explains the set up of the model. Despite its complex nature many questions about how policy affects financial structure and aggregate economic performance can be solved analytically. This is done in Section 3 (General Equilibrium) and Section 4 (Comparative Statics). In Section 5 I calibrate the model with US data and re-assess the quantitative impact of fiscal and monetary policy with a special focus on the credit channel. As a rule I find that financial intermediation through costly banking dampens the long-run effects of fiscal policy somewhat and amplifies those of monetary policy considerably. Turning to temporary but persistent shocks I 
demonstrate in Section 6 that this amplification of monetary policy is also observable in the short run.

\section{The Model}

The Economy consists of four sectors: firms, banks, households, and government. Firms rent factors from households, sell goods to households, and borrow money from banks. Banks take deposits from households and lend money to firms. Households rent capital and labor to firms and hold wealth in form of shares of firm equity, deposits at banks, and cash to buy goods. The government consists of a fiscal and a monetary authority. The fiscal authority controls a set of taxes on income of firms (corporations) and households. The monetary authority controls the nominal interest rate and the reserve ratio. The following subsections describe the four sectors in detail. Because the model is quite complex and notation intensive, Table 1 keeps track of all names assign to variables and parameters.

2.1. Banks. At a time period $t$ banks hold money reserves $M_{t}^{B}$, accept deposits $d_{t}$ from households, and lend loans $\ell_{t}$ to firms. The aggregate view allows to ignore household borrowing and to model a representative household as a lender. Banks pay a nominal interest rate $i_{t}^{D}$ on deposits and demand and a nominal interest $i^{L}$ on loans. Following Diaz-Gimenez et al. (1992) the banking technology is reflected by a cost $\beta_{D}$ on each unit of deposits and a cost of $\beta_{L}$ on each unit of loans. Banks face a reserve requirement at ratio $\epsilon$, which is set by the central bank. Profits of banks are thus given by

$$
\left(1+i_{t}^{L}\right) \cdot \ell_{t}+M_{t}^{B}-\left(1+i_{t}^{D}\right) \cdot d_{t}-\beta_{D} d_{t}-\beta_{L} \ell
$$

Banks operate under perfect competition and free entry such that profits are zero in equilibrium. Insert reserve requirements $M_{t}=\epsilon d_{t}$ and budget constraint $\ell_{t}+M_{t}^{B}=d_{t}$ into the profit equation to get the equilibrium condition on borrowing and lending rates:

$$
i_{t}^{D}=(1-\epsilon)\left(i_{t}^{L}-\beta_{L}\right)+\beta_{D}
$$

The generally positive correlation between borrowing and lending becomes stronger for stricter reserve requirements. In order to investigate the power of this association in driving macroeconomic aggregates we will also sometimes ignore it and assume an uncorrelated evolution of $i_{t}^{L}$ and $i_{t}^{D}$. 
2.2. Firms. The economy is populated by a continuum of competitive firms with measure one. In period $t$ a firm $i \in[0,1]$ operates a c.r.s. technology to produce output

$$
Y_{t}(i)=\omega_{t}(i) F\left(K_{t}(i), A_{t} L_{t}(i)\right)
$$

The inputs are capital, $K_{t}(i)$, and labor $L_{t}(i)$. The deterministic function $F$ exhibits positive and decreasing marginal returns and fulfils the Inada conditions. $A_{t}$ denotes the current level of technology, i.e. aggregate productivity faced by all firms. Production is also subject to an idiosyncratic productivity shock $\omega_{t}(i)$ with mean one, distribution function $\phi$, and density function $\Phi$.

Each unit of labor receives a wage $w_{t}$ and each unit of capital receives an interest rate $r_{t}$ so that total factor costs are given by $X_{t}(i)=w_{t} L_{t}(i)+r K_{t}(i)$. Capital consists of equity capital $K_{t}^{E}(i)$ and capital rented from households, $K_{t}^{H}(i)$. It depreciates at rate $\delta$. The wage bill and the costs of rented capital have to be payed upfront before production and sales commence and before the idiosyncratic productivity shock is observed. They are are financed by one-period debt borrowed from banks. Because there exist the possibility of bankruptcy, banks require a risk premium $i_{t}^{R}$ on top of the lending rate $i_{t}^{L}$.

The credit market is built upon Townsend's (1979) theory of costly state verification. External parties can observe the shock $\omega_{t}(i)$ only by paying a monitoring cost proportional to the project size, $\mu X_{t}(i)$. In case of default the bank seizes all output. Otherwise the loan is repaid with interest and the firm keeps excess output. The possibility of bankruptcy implies that output is sold at a higher price than production costs in order to cover the expected bankruptcy costs. In other words, factor prices are below their marginal products. Output prices are normalized to one. Let $s_{t}>1$ denote the mark-up so that expected output sells at $F\left(K_{t}(i), A_{t} L_{t}(i)\right)=F_{K t} K_{t}(i)+F_{L t} L_{t}(i)=$ $s_{t}\left(r_{t} K_{t}(i)+w_{t} L_{t}(i)\right)$ and factor prices are given by

$$
r_{t}=\frac{F_{K t}}{s_{t}}, \quad w_{t}=\frac{F_{L t}}{s_{t}}
$$

The markup is obtained in equilibrium such that sales cover factor costs, return on equity, and the costs of debt finance. It converges to 1 when the debt ratio converges to zero, i.e. when the model converges towards the standard neoclassical growth model. The higher the debt ratio and thus the probability of bankruptcy for any given shock $\omega_{t}(i)$, the higher the agency costs of debt and thus $s_{t}$. This way, the markup indicates the costs of leverage in the economy. 
Contracts between firms and banks specify the critical shock value $\bar{\omega}_{t}(i)$ that triggers bankruptcy. Since net worth, $N_{t}(i)=\left(1+r_{t}-\delta\right) K_{t}^{E}(i)$, is given at the beginning of period, the critical $\bar{\omega}_{t}(i)$ indirectly determines the total amount borrowed, $X_{t}(i)-N_{t}(i)$, and thus total factor input and production of period $t$. In order to see this clearly let $f\left(\bar{\omega}_{t}(i)\right)$ define the share of output that firm $i$ expects to receive.

$$
f\left(\bar{\omega}_{t}(i)\right)=\int_{\bar{\omega}_{t}(i)}^{\infty}\left(\omega_{t}(i)-\bar{\omega}_{t}(i)\right) \phi\left(\omega_{t}(i)\right) \mathrm{d} \omega_{t}(i)=\int_{\bar{\omega}_{t}(i)}^{\infty} \omega_{t}(i) \phi\left(\omega_{t}(i)\right) \mathrm{d} \omega_{t}(i)-\left[1-\Phi\left(\bar{\omega}_{t}(i)\right)\right] \bar{\omega}_{t}(i) .
$$

For later reference note that firms receive a lower share when they contract at a higher default value, i.e. $f^{\prime}\left(\bar{\omega}_{t}(i)\right)=\Phi\left(\bar{\omega}_{t}(i)\right)-1<0$, and that this effect is increasing with increasing risk, i.e. $f^{\prime \prime}\left(\bar{\omega}_{t}(i)\right)=\phi\left(\bar{\omega}_{t}(i)\right)>0$.

A bank expects to receive the output share

$$
g\left(\bar{\omega}_{t}(i)\right)=\int_{0}^{\bar{\omega}_{t}(i)} \phi\left(\omega_{t}(i)\right) \omega_{t}(i) \mathrm{d} \omega_{t}(i)-\mu \Phi\left(\bar{\omega}_{t}(i)\right)+\left[1-\Phi\left(\bar{\omega}_{t}(i)\right)\right] \bar{\omega}_{t}(i) .
$$

where the first term on the right hand side is the expected return in case of default, the second term is expected monitoring costs, and the last term is the expected share of output from a surviving firm. Subtracting the shares of firm and bank from one provides the deadweight loss (i.e. the agency costs) of debt finance:

$$
1-f\left(\bar{\omega}_{t}(i)\right)-g\left(\bar{\omega}_{t}(i)\right)=\mu \Phi\left(\bar{\omega}_{t}(i)\right) .
$$

The debt contract specifies a critical value for default, $\bar{\omega}_{t}(i)$, such that a firm maximizes expected returns, $f\left(\bar{\omega}_{t}(i)\right) s_{t} X_{t}(i)$, and a bank on average receives the loan back and an interest payment at rate $i_{t}^{L}$. This requires that $s_{t} g\left(\bar{\omega}_{t}(i) X_{t}(i)=\left(1+i_{t}^{L}\right)\left(X_{t}(i)-N_{t}(i)\right)\right.$. The optimal debt contract thus solves

$$
\max _{\bar{\omega}(i)} s f\left(\bar{\omega}_{t}(i)\right) X_{t}(i)=\max _{\bar{\omega}(i)} \frac{s f\left(\bar{\omega}_{t}(i)\right)\left(1+i_{t}^{L}\right)}{1+i_{t}^{L}-s_{t} g(\bar{\omega}(i))} N_{t}(i) .
$$

From the first order condition we obtain an equation that implicitly determines the critical value of default.

$$
s_{t}=\frac{1+i_{t}^{L}}{1-\mu \Phi\left(\bar{\omega}_{t}(i)\right)+\mu \phi\left(\bar{\omega}_{t}(i)\right) \cdot \frac{f\left(\bar{\omega}_{t}(i)\right)}{f^{\prime}\left(\bar{\omega}_{t}(i)\right)}} .
$$

Note that a firm's critical value of default $\bar{\omega}_{t}(i)$ is independent from the size of the project (due to the c.r.s. technology). It depends only on the lending rate $i_{t}^{L}$ and the markup $s_{t}$, which are obtained on the credit and factor markets and are thus independent from idiosyncratic risk for a 
particular firm $i$. In other words, firms are ex ante identical and receive the same debt contract. Consequently, the firm index will be dropped.

In fact, a firm borrowing $\left(X_{t}-N_{t}\right)$ according to the contract specified above commits to repay $\left(1+i_{t}^{R}\right) \cdot\left(1+i_{t}^{L}\right) \cdot\left(X_{t}-N_{t}\right)$ and defaults if $\omega_{t} X_{t}<\left(1+i_{t}^{L}\right) \cdot\left(1+i_{t}^{R}\right)\left(X_{t}-N_{t}\right)=\bar{\omega}_{t} X_{t}$. This implies that the risk premium is $i_{t}^{R}=\bar{\omega}_{t} /\left[s_{t} g\left(\bar{\omega}_{t}\right)\right]-1$. In order to focus on the interesting case where markup and default value are positively correlated we make the following assumption.

Assumption 1. The hazard rate, $\phi(\bar{\omega}) /[1-\Phi(\bar{\omega})]$, is increasing in $\bar{\omega}$.

According to the model's description so far, debt finance has created only costs. In order to create a counterbalancing benefit of debt we assume that firms are corporations so that they face different taxes than households (shareholders). In particular the fiscal system is assumed to create a tax advantage of debt. We begin with deriving - in analogy to Carlstrom and Fuerst (1997) the internal rate of return on equity, $\chi_{t}$. Since debt services are tax deductible accounting profits are given by $s_{t} f\left(\bar{\omega}_{t}\right) X_{t}-i_{t}^{L}\left(1-s_{t} f(\bar{\omega})\right) X_{t}$ and thus by

$$
\chi_{t}(i) \cdot N_{t}(i), \quad \text { where } \quad \chi_{t}(i) \equiv \frac{s_{t} \cdot f\left(\bar{\omega}_{t}(i)\right)}{\left(1+i_{t}^{L}\right)-s_{t} \cdot g\left(\bar{\omega}_{t}(i)\right)} .
$$

Note that in a world without debt finance (the standard neoclassical growth model) we would have that $s_{t}=f=1$ and $g=0$. Thus $\chi_{t}=1$ implying that the firm gets "just" the usual return on capital, $N_{t}(i)=\left(1+r_{t}-\delta\right) K_{t}^{E}(i)$. With debt finance the return on equity has to be higher, $\chi_{t}>1$ since firms have to make up for the costs of possible bankruptcy. This way, $\chi_{t}$ operates as another indicator of leverage. Observe that the internal rate of return is decreasing in the lending rate, $\partial \chi_{t} / \partial i_{t}^{L}<0$.

Given the one-period time series for the costs of production factors and for the costs debt, firms solve the intertemporal problem of maximizing shareholder value. Because firms maximize value in favor of households, net dividends and capital gains are discounted by the rate relevant for households. This is the net rate of return that households get from renting their capital to firms. ${ }^{1}$ Let $D_{t}$ denote dividends in period $t, \tau_{r}$ the tax on corporate profits, and $\tau_{p}$ the tax rate on private

\footnotetext{
${ }^{1}$ Without difficulty and further insight we could add households' holding of riskless bonds and let the corporations' discount rate equal the real rate of returns on bonds. It is also implicitly assumed that retained earnings are always the preferred source of equity accumulation. This assumption is not completely innocuous but made for simplification. Sinn (1987, Ch. 4.2) argues that it should always be fulfilled under the U.S. tax system. Empirical evidence, however, is somewhat less conclusive, see Auerbach (2002).
} 
interest income. A firm's present market value is then given by

$$
V_{0}=E_{0} \sum_{t=0}^{\infty} \prod_{j=0}^{t}\left[1+\left(1-\tau_{p}\right)\left(r_{j}-\delta\right)\right]^{-j} \cdot D_{t} .
$$

Dividends are defined as net profits minus retained earnings. Accounting profits are given by net return on equity times equity utilized, $\left[\chi_{t} \cdot\left(1+r_{t}-\delta\right)-1\right] K_{t}^{E}$, which would reduce to the familiar expression for capital income if there were no debt finance $\left(K^{E}=K\right)$ and no asymmetric information $\left(\chi_{t}=1\right)$. Let $\tau_{r}$ denote the tax rate on corporate income so that net profits are given by $\left(1-\tau_{r}\right)\left[\chi_{t} \cdot\left(1+r_{t}-\delta\right)-1\right] K_{t}^{E}$. Retained earnings constitute investment into equity capital which thus evolves according to

$$
K_{t+1}^{E}=\left(1-\tau_{r}\right)\left\{\left[\chi_{t} \cdot\left(1+r_{t}-\delta\right)-1\right] K_{t}^{E}-D_{t}\right\}+K_{t}^{E}
$$

Again, if there were no debt finance, no asymmetric information, and no corporate taxes, the equation would reduce to the familiar $K_{t+1}=(1-\delta) K_{t}-D_{t}$, with $D_{t}$ denoting consumption out of capital income.

A firm uses the control variables of dividend $D_{t}$ and equity accumulation $K_{t+1}^{E}$ to maximize shareholder value (7) subject to the equation of motion (8) taking tax parameters, interest rates, and $\chi_{t}$ as implied by the each period's debt contract as given. In the Appendix it is shown that the first order conditions can be reduced to the following requirement.

$$
\left(1+r_{t}-\delta\right) \chi_{t}=1+\left(r_{t}-\delta\right) \frac{1-\tau_{p}}{1-\tau_{r}}
$$

This expression provides a unique and positive correlation between the return on capital $r_{t}$ and the internal rate of return $\chi_{t}$. The specific correlation depends on the design of the tax law. Inspection shows that for any positive net return on capital the tax term on the right hand side has to be larger than one for $\chi_{t}>1$. This is the case when $\tau_{r}-\tau_{p}>0$, which constitutes the familiar condition on the tax advantage of debt finance. ${ }^{2}$ The result is very intuitive recalling that $\chi_{t}>1$ indicates that parts of a firm's input bill are financed by costly debt. Henceforth we assume that there is indeed a tax advantage of debt as documented for the US and many other OECD countries

\footnotetext{
${ }^{2}$ A detailed condition on tax advantage of debt would also integrate taxes on capital gains and investment tax credits as, for example, in Sinn (1987) or Strulik (2008). Since the current four-sector model is quite involved already these elements are neglected to keep the analysis simple. Modelling nominal capital gains tax in a monetary model would indeed complicate the analysis considerably. Gavin et al. (2007) have integrated such a tax in an otherwise simpler model and concluded that the effects generated through the interplay between capital gains taxes and monetary policy are negligible with stable inflation.
} 
in, for example, OECD (1991) and Graham (2000, 2006).

Assumption 2. There exists a tax advantage of debt, $\tau_{r}-\tau_{p}>0$.

Holding $r_{t}$ constant, one sees that $\chi_{t}$ gets larger with rising tax advantage $\tau_{r}-\tau_{p}$, indicating that a larger part of the input bill is debt financed. Note also that $\chi_{t}$ and the nominal interest rate requested by banks determine the specifics of the debt contract and thus the mark up on factor costs through (5) and (6). Condition (9) thus reflects the interaction of monetary and fiscal policy in the corporate sector.

2.3. Households. Households derive utility from consumption of goods and leisure. In order to introduce a second angle through which monetary policy matters we assume that a part of the goods must be paid by currency. Let $C_{1}$ denote cash goods, $C_{2}$ credit goods, and $L$ labor supply. The households' problem of intertemporal utility maximization then reads

$$
\max \sum_{t=0}^{\infty} \beta^{t} U\left(C_{1, t}, C_{2, t}, 1-L_{t}\right) .
$$

Utility $U$ is assumed to be concave in all its arguments.

Households earn labor income $w_{t}$, taxed at rate $\tau_{w}$, and capital income. Being simultaneously holder of stocks of firms, capital rented to firms, and of funds supplied to firms via banks, households earn dividends net of taxes $D$, returns on capital stock $K^{H}$, and returns on deposits at banks. Furthermore households hold money $M^{H}$ and receive transfers $T$. Their budget constraint in real terms is thus given by the following expression.

$$
\begin{aligned}
& \frac{M_{t+1}^{H}}{p_{t}}+\frac{d_{t+1}}{p_{t}}+K_{t+1}^{H}= \\
& \left(1-\tau_{w}\right) w_{t} L_{t}+\left(1-\tau_{p}\right) i_{t}^{D} \frac{d_{t}}{p_{t}}+\left(1-\tau_{p}\right)\left(r_{t}-\delta\right) K_{t}^{H}+D_{t}+\frac{d_{t}}{p_{t}}+K_{t}^{H}+\frac{M_{t}^{H}}{p_{t}}+T_{t}-C_{1, t}-C_{2,1} .
\end{aligned}
$$

In the Appendix it is shown that the first order conditions for maximizing (10) subject to (11) and the cash-in-advance constraint $p_{t} C_{t, 1}=M_{t}$ can be reduced to the following conditions on the temporal and intertemporal allocation.

$$
\begin{aligned}
\frac{U_{c}\left(C_{2, t}\right)}{U_{c}\left(C_{2, t+1}\right)} & =\beta\left[1+(1-\tau)\left(r_{t+1}-\delta\right)\right] \\
U_{c}\left(C_{1, t}\right) & =\left[1+\left(1-\tau_{p}\right) i_{t}^{D}\right] U_{c}\left(C_{2, t}\right)
\end{aligned}
$$




$$
\frac{U_{L}}{U_{c}\left(C_{2, t}\right)}=\left(1-\tau_{w}\right) w_{t}
$$

where $U_{c}\left(C_{i, t}\right)$ is shorthand notation for $\partial U\left(C_{1, t}, C_{2, t}, 1-L_{t}\right) / \partial C_{i, t}, i=1,2$. Equation (12a) is the familiar Ramsey rule. Here it applies unconditionally only for credit goods. Inserting (12b) into (12a) one sees that in case of cash goods the Ramsey rule holds only if interest rates on bank deposits are expected not to change $\left(i_{t+1}^{D}=i_{t}^{D}\right)$. If households expect for next period higher nominal interest rates, i.e. higher opportunity costs of cash holdings and thus of cash good consumption, they react by transferring future cash good consumption to the present. Within a period, condition $(12 \mathrm{~b})$ indicates that credit good consumption rises $\left(U_{c}\left(C_{2, t}\right)\right.$ falls $)$ relative to cash good consumption when opportunity costs of money holding $\left(i_{t}^{D}\right)$ increase. Finally, condition (12c) specifies the optimal labor supply for given net labor income.

In the Appendix it is also shown that households' no-arbitrage as established by the first order conditions produces a unique correspondence between nominal and real interest rates and inflation, known as the Fisher equation.

$$
\frac{p_{t+1}}{p_{t}}=\frac{1+\left(1-\tau_{p}\right) i_{t+1}^{D}}{1+\left(1-\tau_{p}\right)\left(r_{t+1}-\delta\right)} .
$$

The extent of inflation depends on the differential between nominal and real interest rates. Since we have assumed that the monetary authority controls the nominal interest rate, inflation is uniquely determined by no-arbitrage in the household sector and, as in Carlstrom and Fuerst (2001), there is no separate role of inflation in general equilibrium once the monetary authority has fixed the nominal interest rate. Taking the derivative with respect to $\tau_{p}$ it is straightforward to verify that the sign of $\partial\left(p_{t+1} / p_{t}\right) / \partial \tau_{p}$ is inversely correlated with the sign of the interest rate differential $i_{t}-\left(r_{t}-\delta\right)$. This result reflects another interaction of monetary and fiscal policy, now at the household's side. Whenever inflation exists, a cut of capital taxes further spurts inflation as long as the monetary authority keeps the nominal interest rate constant. In this case a cut of capital income taxes overproportionally affects capital holdings, i.e. besides accumulating more of both assets, households also shift wealth from deposit holdings to real assets.

2.4. Government. The government demands a constant share $g_{s}$ of GDP which is used unproductively for public consumption and financed by tax revenue (including seignorage). Excess revenue is rebated to households through transfers $T$. The monetary authority sets the reserve ratio $\epsilon$ and the nominal interest rate. Taking optimal behavior of banks (1) into account the monetary author- 
ity can control at most one interest rate. Here we assume that it controls $i^{D}$ and distinguish two cases. Either the government sets the interest rate directly (which is then treated parametrically) or it follows an interest rule (14).

$$
\hat{i}_{t}=\rho \cdot \hat{i}_{t-1}+\epsilon_{t}^{i}, \quad 0<\rho<1,
$$

where $\hat{i}_{t}$ is the log deviation of the nominal interest rate from steady-state and $\epsilon_{t}^{i}$ is a nominal interest rate shock.

\section{TABle 1: VARIABles AND PARAMEters}

\begin{tabular}{|c|c|c|c|}
\hline \multicolumn{4}{|c|}{ Variables } \\
\hline$A$ & technology level & $b$ & debt ratio, $b \equiv 1-f(\bar{\omega})$ \\
\hline$C_{1}$ & consumption of cash good & $c_{1}$ & consumption of cash good in efficiency units \\
\hline$C_{2}$ & consumption credit good & $c_{2}$ & consumption of credit good in efficiency units \\
\hline$D$ & dividends & $d$ & deposits \\
\hline$I$ & net investment & $i^{L}$ & nominal interest rate on loans \\
\hline$K$ & capital stock & $k$ & capital in efficiency units, $k \equiv K /(A L)$ \\
\hline$K^{E}$ & equity capital & $\ell$ & loans \\
\hline$K^{H}$ & capital rented from households & $p$ & price level \\
\hline$L$ & employment & $r$ & real interest rate \\
\hline$M^{B}$ & money reserves & $r^{L}$ & risk premium \\
\hline$M^{H}$ & cash holdings by households & $s$ & markup factor \\
\hline$N$ & net worth & $w$ & wage rate \\
\hline$P$ & profits & $\pi$ & inflation rate \\
\hline$V$ & firm value & $\chi$ & internal rate of return on equity \\
\hline$W$ & total financial wealth of households & $\omega$ & idiosyncratic productivity shock \\
\hline$X$ & project size & $\bar{\omega}$ & critical default value \\
\hline$Y$ & output & $i$ & index for firm \\
\hline$t$ & index for time & $j$ & auxiliary index for time \\
\hline \multicolumn{4}{|c|}{ Parameters: technologies and preferences } \\
\hline$\alpha$ & production elasticity of capital & $\eta$ & weight of cash goods in utility \\
\hline$\beta$ & time discount factor & $B$ & weight of leisure in utility \\
\hline$\beta^{D}$ & unit costs of deposits & $\mu$ & bankruptcy costs, fraction of project size \\
\hline$\beta^{L}$ & unit costs of loans & $\sigma_{\omega}$ & standard deviation of productivity shock \\
\hline$\delta$ & depreciation rate & & \\
\hline \multicolumn{4}{|c|}{ Parameters: policy } \\
\hline$g_{s}$ & government share of GDP & $T$ & transfers to households \\
\hline$\tau_{p}$ & tax rate on private capital income & $\epsilon$ & reserve ratio \\
\hline$\tau_{r}$ & tax rate on corporate profits & $i^{D}$ & nominal interest rate on deposits \\
\hline$\tau_{w}$ & tax rate on labor income & $\rho$ & autocorrelation coefficient of interest rate rule \\
\hline
\end{tabular}

The following symbols are used for functions. $F$ : production, $f$ : equity's share of output, $g$ debt's share of output, $\Phi$ : cdf of productivity shock, $\phi$ : pdf of productivity shock. 


\section{General Equilibrium}

Economy-wide production $F\left(K_{t}, A_{t} L_{t}\right)$ is obtain from aggregating (2) over firms. From aggregate output a share of $\mu \Phi\left(\bar{\omega}_{t}\right)$ is lost in form of bankruptcy costs. From the remainder (i.e. the GDP) the government uses a share of $g_{s}$ for public consumption so that the economy's aggregate budget constraint reads $F\left(K_{t}, A_{t} \cdot L_{t}\right)\left[1-\mu \Phi\left(\bar{\omega}_{t}\right)\right]\left(1-g_{s}\right)=C_{1, t}+C_{2, t}+K_{t+1}-(1-\delta) K_{t}$. Let $k_{t}$ and $c_{t}$ denote capital and consumption in efficiency units, $k_{t} \equiv K_{t} /\left(A_{t} L_{t}\right)$ and $c_{i, t} \equiv C_{i, t} /\left(A_{t} L_{t}\right), i=1,2$. Using the new notation the aggregate budget constraint can be rewritten as follows.

$$
k_{t+1}=F\left(k_{t}, 1\right)[1-\mu \Phi(\bar{\omega})]\left(1-g_{s}\right) k_{t}+(1-\delta) k_{t}-c_{1, t}-c_{2, t} .
$$

The equilibrium on capital and credit markets is formally described by equations (3), (5), (6), and (9), which implicitly determine the set $\left(\omega_{t}, s_{t}, \chi_{t}, r_{t}\right)$. In the Appendix it is shown that the sign of correlations between real and financial variables is unambiguously determined and the following holds true.

\section{LEMMA 1. In general equilibrium}

$$
\frac{\partial \bar{\omega}_{t}}{\partial s_{t}}>0, \frac{\partial \chi_{t}}{\partial s_{t}}>0, \frac{\partial s_{t}}{\partial r_{t}}>0, \frac{\partial r_{t}}{\partial k_{t}}<0
$$

Intuitively these results show that a higher return on capital $r_{t}$ leads to higher investment for any given stock of equity. This implies higher leverage and higher bankruptcy risk and is thus reflected by a higher default value $\bar{\omega}_{t}$ on which firms and banks contract. Higher costs of debt are captured by a higher internal rate of return $\chi_{t}$ and a higher markup on factor costs $s_{t}$.

Although there is no simple condition linking capital stock and capital return anymore (like $r=F_{K}$ in the basic neoclassical model), the association between capital stock and capital return continues to be unambiguously negative. This result is essential for stability of the economic system. For an intuition imagine an economy below its long-run steady-state that accumulates capital. As in the standard growth model more capital accumulation implies a tendency for productivity $F_{K}$ to fall. With contrast to the standard model this is not yet sufficient to claim decreasing interest rates, as evident from equation (3). In addition, capital accumulation lowers the value of equity capital and through this channel the incentive for firms to expand through costly debt finance. Firms thus require a smaller share of debt and contract with banks at lower $\bar{\omega}$. A lower default value $\bar{\omega}$ implies a lower markup rate $s$ and lower internal rate of return $\chi$. This 
in turn necessarily implies a lower interest rate $r$ according to (9). The result that both, $r_{t}$ and $s_{t}$ are decreasing with capital accumulation reflects the lower overall lower scarcity of capital.

The model has no analytical solution for general instantaneous utility. As Cooley and Hansen (1992), Carlstrom and Fuerst (2001) and many others we thus proceed by assuming a log-linear form of utility.

$$
U=\eta \log C 1, t+(1-\eta) \log c_{2, t}-B L,
$$

where $\eta$ determines the relative importance of cash goods in utility. Employing condition (12b) we get a unique solution for the ratio of cash goods in consumption,

$$
c_{1, t}=\frac{\eta}{(1-\eta)\left[1+\left(1-\tau_{p}\right) i_{t+1}^{D}\right]} \cdot c_{2, t}
$$

Let us begin by assuming that policy changes are discrete events such that policy variables can be treated parametrically (we return later to the the discussion of interest rate rules). In this case the model can be represented by the following two-dimensional dynamic system in the $\left(k_{t}, c_{2, t}\right)$-space.

$$
\begin{aligned}
k_{t+1} & =F\left(k_{t}, 1\right)[1-\mu \Phi(\bar{\omega})]\left(1-g_{s}\right)+(1-\delta) k_{t}-c_{2, t}-\frac{\eta}{1-\eta}\left[1+\left(1-\tau_{p}\right) i^{D}\right]^{-1} c_{2, t} \\
c_{2, t+1} & =\beta\left[1+\left(1-\tau_{p}\right)\left(r_{t+1}-\delta\right)\right] c_{2, t} .
\end{aligned}
$$

The reduced form of the model consists of the above two-dimensional system of difference equations for $k$ and $c_{2}$ and a system of equations (3), (5), (6), and (9) that - together with the distribution function for $\omega$-implicitly determines $r\left(k_{t}\right)$ and $\bar{\omega}\left(k_{t}\right)$. Thus $k$ is the unique state variable. From (20) we see that at the steady-state the net interest rate equals the growth-adjusted rate of time preference rate.

$$
r^{*}=\frac{1 / \beta-1}{1-\tau_{p}}+\delta .
$$

In the Appendix it is shown that the steady-state $\left(k^{*}, c_{2}^{*}\right)$ is a saddle-point. Transitional dynamics are uniquely determined by the stable arm along which $c_{t}$ and $k_{t}$ rise for adjustment from below steady-state values. Apply Lemma 1 to see that in a growing economy firms become less leveraged and bankruptcy rates and mark-ups decrease. The equity ratio of the average firm rises as the economy develops and capital productivity and interest rates decrease. Consequently, banks demand lower risk premia and firms negotiate lower default values $\bar{\omega}_{t}$. The mark-up $s_{t}$ decreases at higher stages of development. From decreasing bankruptcy rates along the adjustment path, 
however, we cannot conclude overall falling costs debt finance. Of the total costs of debt finance $\mu \Phi\left(\bar{\omega}_{t}\right) \cdot F\left(K_{t}, A_{t} L_{t}\right)$, the first term $\Phi\left(\bar{\omega}_{t}\right)$ unambiguously decreases because of lower risk of bankruptcy. The second term, total size of production, i.e. the input bill, increases. At higher stages of development the representative firm is bigger. Because total costs are a compound of (decreasing) individual risk and (rising) firm size, the overall affect is ambiguous.

\section{Comparative Statics}

Because the real interest rate at the steady-state is by fixed by (21) we obtain a unique $k^{*}$ from $r=F_{K} / s\left(r^{*}\right)$. By (19) this fixes credit good consumption at

$$
c_{2}^{*}=\frac{F\left(k^{*}\right)(1-\mu \Phi(\bar{\omega}))\left(1-g_{s}\right) k^{*}-(\delta+\gamma) k^{*}}{1+\frac{\eta}{1-\eta}\left[1+\left(1-\tau_{p}\right) i^{D}\right]^{-1}} .
$$

Cash good consumption follows as a positive multiple from (18) and steady-state employment can then by inferred from (12c) as

$$
L^{*}=\frac{(1-\eta)\left(1-\tau_{w}\right)(1-\alpha)\left(k^{*}\right)^{\alpha}}{B c_{2}{ }^{*}}
$$

At the financial side, the steady-state interest rate fixes the internal rate of return as uniquely determined by parameters of time preference and various fiscal policy measures.

$$
\chi^{*}=\frac{1+\left(r^{*}-\delta\right) \frac{1-\tau_{p}}{1-\tau_{r}}}{1+r^{*}-\delta}
$$

These results can be exploited to derive the comparative statics of fiscal and monetary policy.

\subsection{Fiscal Policy.}

Proposition 1. A permanent cut of the tax rate on corporate income implies in the long-run: (i) lower internal rate of return on equity, (ii) lower bankruptcy rate, (iii) lower mark-up on factor costs, (iv) higher equity ratio, (v) higher capital stock, (vi) higher wages, and (vii) higher consumption of both goods.

Proof. Inspect (22) to obtain $\partial \chi^{*} / \partial \tau_{r}>0$. Then, conclude (ii) and (iii) from Lemma 1. The equity ratio is given by $f(\omega)$ with $f^{\prime}>0$, which implies (iv). Because $s^{*}$ decreases and $r^{*}$ remains constant, $F_{K}$ must decrease for (3) to be fulfilled. This implies (v). Due to the neoclassical features of production a higher capital stock implies higher marginal product of labor, $F_{L}>0$. Together with a lower mark-up this implies increasing wages because of (3). Finally, higher consumption 
follows from (22).

Note that all these results are unobservable in a the standard neoclassical growth model (without corporate sector and financial intermediation) since the tax cut does not affect the real interest rate. Here, a lower tax on retained earnings reduces the tax advantage of debt and lowers debt demand. A lower value of $\chi^{*}$ reflects this adjustment of capital structure towards a higher equity ratio. Less leverage implies less bankruptcy risk, and firms and banks contract at a lower $\bar{\omega}^{*}$. Lower bankruptcy rates and lower agency costs imply a smaller mark-up on factor costs. Because of lower costs of finance (reflected by a smaller $s^{*}$ ), capital is employed more efficiently than before the reform and firms raise investment and capital stock. Formally, $F_{K}$ decreases simultaneously with $s$ in equation (3). With rising $k$, output, wages and consumption increase. Moreover, since less of output is spent on costs of debt, the share of output available for consumption gets bigger, implying a second positive effect from the coporate tax reduction.

Likewise, a cut of $\tau_{p}$ entails the following long-run consequences.

Proposition 2. A permanent cut of the tax rate on private capital income leads to a higher internal rate of return on equity, a higher mark-up on factor costs, a lower equity ratio, and a higher bankruptcy rate.

Proof. Obtain $\partial \chi^{*} / \partial \tau_{p}<0$ from (22). A lower private income tax decreases the incentive for equity financed investment and increases the tax advantage of debt finance. From Lemma 1, higher demand for debt is reflected by a higher internal rate of return on equity, a higher mark-up, and a higher critical value for default, which implies a lower equity ratio.

By itself these reactions on the financial side would feed back negatively on real macroeconomic behavior through higher bankruptcy rates and higher costs of debt. However, now the familiar savings channel is also operative since the tax cut lowers the after-tax real interest rate. This "usual" effect by itself is expansive and numerical exploration of the model has to determine which effect dominates.

4.2. Monetary Policy. At the steady-state neither the real interest rate $r^{*}$ nor the internal rate of return $\chi^{*}$ are affected by monetary policy. Nevertheless monetary policy has quite strong real consequences via two channels that are reinforcing each other through the banking system. In order to disentangle effects it may be helpful to begin with considering the hypothetical cases 
of isolated changes of $i^{D}$ or $i^{L}$, i.e. by ignoring the interaction through the banking equilibrium condition (1).

Proposition 3. A permanent unilateral cut of the nominal interest rate on deposits increases aggregate production, employment, and consumption of cash goods. It leaves consumption of credit goods and the financial side of the economy unaffected.

Proof. Note from (21) and (24) that $r^{*}$ and $\chi^{*}$ are unaffected by a cut of $i^{D}$ implying unchanged $k^{*}$. Next conclude from (22) and (23) that labor-adjusted consumption of credit goods $c_{2}$ falls and employment rises. The linear relationship between $c_{2}^{*}$ and $L^{*}$ implies that consumption $C_{2}^{*}$ remains unchanged. Since $k^{*}$ is unaffected and $L^{*}$ rises, aggregate output $Y^{*}=L^{*} f\left(k^{*}\right)$ is higher in the new equilibrium. Since the steady-state investment rate $\delta k^{*}$ is unaffected, consumption of credit goods must be higher at the new steady-state.

Proposition 3 shows how the efficiency gains from a lower "inflation tax" on capital and labor income are causing higher savings and labor supply. These effects are well understood and investigated by most authors of monetary policy analysis in the neoclassical growth framework.

Next consider a unilateral change of $i^{L}$. Such a policy remained unexplored by Carlstrom and Fuerst (2001), by Cooley and Hansen (1992), and by most other studies in the neoclassical paradigm. $^{3}$

Proposition 4. A permanent unilateral cut of the nominal interest rate on loans increases output, employment, and consumption. It reduces the markup on factor costs but leaves the steadystate debt ratio and other financial variables unaffected.

Proof. Begin with inserting (5) into (6) which eliminates $s$ and $1+i^{L}$ so that (6) becomes a unique function of the critical default value, $\chi(\bar{\omega})$. Since $\chi^{*}$ is unaffected by the policy, which can be concluded from $(24), \bar{\omega}^{*}$ is also unaffected. Thus, the steady-state debt ratio $1-f\left(\bar{\omega}^{*}\right)$ does not change. Next conclude that $s^{*}$ has to be lower in the new steady-state for (5) to be fulfilled at lower $i^{L}$. Then infer from (3) that factor productivities are lower for higher $s^{*}$. Since the production function is concave with $F_{K}=F^{\prime}(k, 1), k^{*}$ has to be higher at the new steadystate. Finally conclude higher consumption and employment from (22) and (23) and thus higher aggregate output $L^{*} f\left(k^{*}\right)$.

\footnotetext{
${ }^{3}$ Macroeconomic effects of a change of the lending rate are investigated by Cooley and Quadrini (2006) although with a different focus than the present paper.
} 
Intuitively, the cut of the nominal lending rate has not changed inherent risk in the economy, which is determined by the distribution of productivity shocks $\omega$. It has, nevertheless, reduced costs of external finance. Firms react to this efficiency gain by charging lower markups on factor costs and employing more capital and labor. We can also, heuristically, infer adjustment dynamics. At the time of the interest rate cut, net worth of firms is given. The generally lower costs of debt induces firms to increase debt demand and contract with banks at higher $\bar{\omega}$. In subsequent periods increasing debt is gradually replaced by equity accumulation, net worth rises, and firms converge towards the original debt ratio which is fixed by economic fundamentals and the tax system. At the new new steady-state firms arrive at the original financial structure but run a higher input bill. On the aggregate, financial structure looks as before but everything on the real side is bigger.

Finally, reintroducing interaction through banking equilibrium and combining the two last propositions we arrive at the following result.

Proposition 5. If nominal interest rates on deposits and loans are positively correlated through banking equilibrium (as in the present model through (1)), the effects that a unilateral change of the interest rate on either deposits or loans causes on aggregate production and employment are amplified through the banking system.

Studies focussing on just one of these channels, i.e. neglecting the interaction, will underestimate the power of monetary policy. Of course, analytically it cannot be decided how large the amplification through the banking sector is. To tackle these and other open problems we now turn towards a numerical analysis of the model.

\section{Quantitative Effects of Fiscal and Monetary Policy}

This section resolves the remaining ambiguities and assesses the quantitative effects of fiscal and monetary policy. For that purpose we consider a calibrated version of the model. Many parameter values are chosen in accordance with the quantitative macroeconomics literature, in particular Carlstrom and Fuerst (2001) and Cooly and Hansen (1992). The remaining parameters are specified such that the model matches stylized empirical facts of the U.S. economy, in particular those on taxes and capital structure suggested by Gordon and Lee (2001, 2007).

The production function is assumed to be of Cobb-Douglas-type with capital share $\alpha=0.36$. The annual rate of depreciation $\delta$ is set to 0.08 and the discount factor $\beta$ to 0.098 , implying an annual rate of time preference of 0.02. Following Cooley and Hansen's suggestion, 84 percent of 
consumption are spent on cash goods, $\eta=0.84$. The parameter $B$ is adjusted such that households spend one third of their time working.

The monetary authority is assumed to control the reserve ratio and the nominal interest rate on deposits. The interest rate on loans follows endogenously from banking equilibrium (1). For illustrative purposes, however, we will ignore this fact from time to time and imagine that the monetary authority could control all nominal rates independently. Monetary policy can either be executed in a discrete manner or by following an interest rate rule. In this section we consider the discrete case and return to the policy rule in Section 6 .

Calibration of the banking sector follows Diaz-Gimenez et al. (1992) by setting the nominal annual interest rates on deposits and loans to $i^{D}=0.04$ and $i^{L}=0.095$ and the unit cost of deposits to $\beta_{D}=0.01$. There is some uncertainty about the appropriate value of $\epsilon$ since "depending on which type of accounts one looks at, average reserve requirements on banks could be anywhere from 2.5 percent to 12 percent" (Chari et al., 1995). This uncertainty is met by setting $\epsilon=0.05$, a parameter in the middle of those used in quantitative studies, and by providing sensitivity analysis towards much higher and lower values. The remaining parameter, the unit costs of loans, is obtained endogenously, $\beta_{L}=0.063$. The imposed nominal interest rates are certainly at the upper end of the empirically plausibly range. I utilize this fact by investigating policies with respect to cuts of interest rates. Additionally, sensitivity analysis checks for robustness of results. Inflation is obtained endogenously from (13). The benchmark parameters imply an annual rate of inflation of one percent.

The tax on labor income $\tau_{w}$ is set to 0.36 as estimated by Carey and Tchilinguirian (2000) for the average effective tax rate on labor income in the U.S. The implied value for the weight of leisure in utility $(B)$ is 1.95 . The government share $g_{s}$ is set to 0.14 . From Gordon and Lee (2001, 2007) I take the average corporate tax of U.S. medium sized firms $\tau_{r}=0.45$ and the tax rate on private capital income $\tau_{p}=0.245$. Gordon and Lee (2001, p. 222) conclude from their estimates to expect that a five percentage increase in the $\left(\tau_{p}-\tau_{r}\right)$ differential raises the debt ratio by about 1.8 percentage points. One experiment will be to check whether the model is capable to produce Gordon and Lee's predicted change of firm leverage after tax reform.

As in Carlstrom and Fuerst (2001) productivity shocks are assumed to be log-normally distributed. Here, however, the internal rate of return cannot be set arbitrarily (through timepreference of entrepreneurs). It is endogenously determined according to (22) by the net interest 
rate and the design of tax rates. For benchmark values we obtain $\chi=1.01$. Facing one degree of freedom less, I take the bankruptcy rate from Carlstrom and Fuerst's calibration $(\Phi(\bar{\omega})=0.04$ per year) and set the equilibrium debt ratio, $b \equiv 1-f(\omega)$, to 0.194 , which is the weighted average for the sample of U.S. corporations in Gordon and Lee's (2001) study. Given these values, markup, risk premium, bankruptcy costs, and the parameters of the log-normal distribution are endogenously determined. For the benchmark parameterization we obtain a markup $s=1.103$, a standard deviation $\sigma_{\omega}$ of 0.76 , a bankruptcy cost parameter $\mu=0.016$, and a risk premium of 1.31 percent. As a consequence of the relatively low imposed debt ratio the estimated bankruptcy cost parameter is relatively small. I provide sensitivity analysis by investigating also a higher initial share of debt implying a higher estimated value of $\mu$. While such a scenario can no longer approximate Gordon and Lee's estimates, it comes closer to the setup by Carlstrom and Fuerst who have assumed relatively high values for both bankruptcy cost and debt ratio.

Table 2 shows the macroeconomic consequences of various fiscal and monetary policies predicted by the model. Besides results for some of the model's original variables I have also calculated the implied values for the investment rate $I / Y$, for output per capita (or productivity) $y=Y / L$, and for aggregate welfare, $x$. As in Lucas (1990), Cooley and Hansen (1992), and many other quantitative studies the welfare gain obtain from a policy change is computed as the constant relative increase in consumption that equates intertemporal utility from remaining at the initial steady-state with intertemporal utility experienced along the consumption path caused by the policy change. The calculation takes the transition towards the new steady-state into account. For that purpose I employ the backward integration method of Brunner and Strulik $(2002,2004)$ which solves adjustment dynamics of the non-linearized system. Changes in levels, i.e. for aggregate output, employment, consumption, and per capita output are shown as relative deviation from the initial steady-state, for example $\Delta Y / Y^{*}$, and are expressed in percent. Changes in ratios, i.e for the investment ratio, the markup, and the debt ratio, are calculated as percentage point deviation from initial steady-state, for example $\Delta b$, since in these cases the absolute change is more informative.

The first row shows consequences of a permanent cut of the private capital income tax by five percentage points keeping the government share constant, i.e. by financing the reform with lump sum transfers. Through the ordinary savings channel the policy leads to higher investment and thus in the long-run to higher output, employment, and consumption. Through the credit channel it leads to a higher tax advantage of debt, a higher debt ratio, a higher markup on factor cost and 
through higher agency costs of debt to lower aggregate consumption. This effect, however, is of second order. The savings channel clearly dominates the results.

Figure 1. Adjustment Dynamics after a 5 Percentage Point Tax Cut $\left(\tau_{p}\right)$
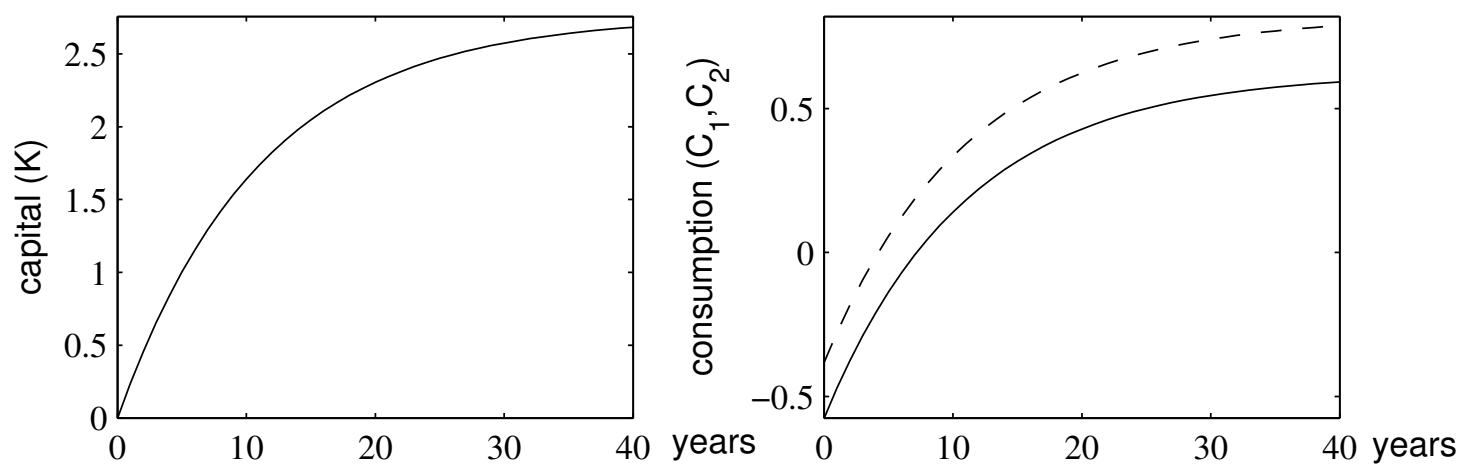

Parameters as below Table 2. Solids lines in right hand side panel: cash good consumption $\left(C_{1}\right)$, dashed lines: credit good consumption $\left(C_{2}\right)$.

The dominance of the savings channel can also be seen by comparing results with those obtained when firms are completely equity-financed, i.e. a Cooley-Hansen version of the model. Results of the second row indicate that neglecting the firm finance decision would lead to a mild overestimation of the long-run impact of the reform. Comparing results with Strulik (2008) who investigated the present model without costly banking and monetary policy shows that neglecting the monetary side also leads to a mild overestimation of results. Intuitively, costly banking causes a higher lending rate, higher agency costs of debt and a higher markup on factor costs. This drives down efficiency of factor use and employment of capital and labor. Yet, the financial effects on real macroeconomic aggregates are of second order compared to savings, a conclusion, which can also be drawn by comparing results with those obtained for a much lower lending rate of $i^{L}=0.06$. A similar robustness of results is obtained against variation of the initial debt ratio as shown in the fourth row of Table 2 .

The tax cut has mildly negative consequences on aggregate welfare. The puzzle why a reform with expansive effects on output and productivity reduces welfare is easily resolved. For once, the positive effect of consumption on utility is counter-balanced by a utility-deteriorating decrease of leisure. Secondly, as visible in Figure 1, the higher incentive to invest causes consumption to fall below initial steady-state level for the first five or, respectively, eight years after the policy change. These years are highly valued by households with positive time preference so that adjustment 
dynamics dominate the generally positive effect of the tax cut on welfare in the long-run, i.e. the utility gain that would occur if households could jump towards the new steady-state. It cannot be concluded from the almost negligible effect on welfare that the policy has no impact. In fact, the long-run macroeconomic effects are quite large; the model predicts an increase of aggregate production of over 1 percent and an increase of productivity by about 0.8 percent.

Table 2: Long-Run Effects of Monetary and Fiscal Policy

\begin{tabular}{cccccccccc}
\hline \hline Experiment & $Y$ & $L$ & $C_{1}$ & $C_{2}$ & $I / Y$ & $y$ & $s$ & $b$ & $x$ \\
\hline$\Delta \tau_{p}=-0.05$ & 1.28 & 0.45 & 0.62 & 0.82 & 0.36 & 0.82 & 0.14 & 2.3 & -0.020 \\
no debt & 1.47 & 0.57 & 0.70 & 0.89 & 0.43 & 0.89 & -- & -- & -0.024 \\
$i^{L}=0.06$ & 1.30 & 0.48 & 0.62 & 0.82 & 0.37 & 0.82 & 0.14 & 2.3 & -0.021 \\
$b=0.25$ & 1.29 & 0.46 & 0.63 & 0.82 & 0.36 & 0.82 & 0.13 & 2.2 & -0.020 \\
\hline$\Delta \tau_{r}=-0.05$ & 0.19 & 0.05 & 0.14 & 0.14 & 0.06 & 0.14 & -0.27 & -3.9 & -0.003 \\
$i^{L}=0.06$ & 0.20 & 0.06 & 0.14 & 0.14 & 0.06 & 0.14 & -0.27 & -3.9 & -0.003 \\
$b=0.25$ & 0.17 & 0.04 & 0.13 & 0.13 & 0.06 & 0.13 & -0.25 & -4.1 & -0.003 \\
\hline$\Delta \tau_{p}=-0.10 \& \Delta \tau_{r}=-0.05$ & 2.60 & 0.89 & 1.30 & 1.70 & 0.74 & 1.70 & 0.01 & 0.1 & -0.042 \\
$\Delta \tau_{p}=-0.06 \& \Delta \tau_{r}=-0.01$ & 1.50 & 0.54 & 0.77 & 1.00 & 0.44 & 1.00 & 0.11 & 1.8 & -0.025 \\
\hline$\Delta i^{D}=-0.01$ & 1.56 & 1.01 & 1.22 & 0.52 & 0.24 & 0.54 & -1.06 & 0.0 & -0.019 \\
$i^{L}=0.06$ & 1.61 & 1.04 & 1.24 & 0.53 & 0.25 & 0.56 & -1.06 & 0.0 & -0.020 \\
$\Delta i_{L}=-0.01\left(\Delta i_{D}=0\right)$ & 0.89 & 0.37 & 0.52 & 0.52 & 0.22 & 0.52 & -1.01 & 0.0 & -0.013 \\
$\Delta i_{D}=-0.01\left(\Delta i_{L}=0\right)$ & 0.62 & 0.62 & 0.74 & 0.00 & 0.00 & 0.00 & 0.00 & 0.0 & -0.005 \\
$\Delta \epsilon=+0.05$ & -0.15 & -0.09 & -0.09 & -0.03 & -0.04 & -0.09 & 0.18 & 0.0 & -0.000 \\
$\Delta \epsilon=-0.05$ & 0.14 & 0.06 & 0.08 & 0.08 & 0.04 & 0.08 & -0.16 & 0.0 & -0.001 \\
\hline \hline
\end{tabular}

Benchmark parameters: $\alpha=0.36, \beta=0.98, \delta=0.08, \eta=0.84, B=1.95, \tau_{r}=0.45, \tau_{p}=0.245$, $\tau_{w}=0.36, g_{s}=0.14, i^{L}=0.095, i^{D}=0.04, \beta_{L}=0.063, \beta_{D}=0.01$. The debt ratio is denoted by $b, b \equiv\left(1-f(\bar{\omega})=0.194\right.$, implying $r_{L}=0.131, \mu=0.018, \sigma_{\omega}=0.76 . I / Y$ denotes the investment rate and $y$ is productivity $Y / L$. Effects on levels are measured relatively, i.e. in percent deviation from pre-reform equilibrium, effects on ratio (i.e. for $I / Y, s, b$, ) are measured in percentage point deviation from initial steady-state value.

The next subset of rows shows results for a corporate tax cut of 5 percent. Such a policy would have no effect at all in a Cooley-Hansen- or Carlstrom-Fuerst type model since there is no corporate sector and no tax advantage of debt. Here, the results confirm the earlier finding obtained from the credit channel model without monetary-financial interaction (Strulik, 2008). A corporate tax cut entails only mild consequences on real macroeconomic aggregates although its impact on the financial side is quite drastic. The model estimates a reduction of the markup by 0.27 percentage points and a fall of the debt ratio by almost 4 percentage points.

Are these strong reactions of the financial side sufficient to conclude that the model overemphasizes the financial consequences of tax reform vis a vis the estimations by Gordon and Lee (2001)? 
Not necessarily. It is important to note that Gordon and Lee have used the tax differential $\left(\tau_{p}-\tau_{r}\right)$ as regressor. Tax cuts frequently come in bundles and interact in their effects on financial and real decisions. From the set of tax changes that cause a five percent fall of the tax differential is the $\left(\Delta \tau_{p}=0.05, \Delta \tau_{r}=0\right)$-policy just one example. If, for example, a five percent reduction of the tax differential was caused by a 10 percent cut of personal taxes and a five percent cut of corporate taxes, the model predicts almost no effect on firm finance. The markup increases by a mere 0.01 percentage points as shown in third subset of policies in Table 2. Results shown in the subsequent row for the $\left(\Delta \tau_{p}=0.06, \Delta \tau_{r}=0.01\right)$-case demonstrate that tax policies can be designed for which the model produces exactly the 1.8 percentage rise of the debt ratio that has been estimated by Gordon and Lee for a five percent increase of the tax differential.

The macroeconomic consequences concluded for fiscal policy can be contrasted with those obtained for monetary policy. In particular, the model suggests quite strong real effects from changes of the nominal interest rate. These are explained and assessed with help of the final subset of experiments in Table 2. The basic experiment reduces the nominal interest rate on loans by one percentage point and predicts, for example, an increase of aggregate production by 1.5 percent and of employment by one percent. Results do not differ much if we originate from a much lower nominal interest on loans. The unexpectedly strong real effects are generated by the banking system, i.e. the fact that a cut of the nominal lending rate also implies, via banking equilibrium, lower nominal interest rates on deposits. In order to disentangle both channels it is again helpful to imagine that the monetary authority could control both interest rates separately.

Consider first a unilateral change of the nominal interest rate on deposits by one percentage point. The third row in the last panel of Table 2 shows that such a reduction of the "inflation tax" entails an increase of output and employment by 0.6 percent. It leaves the financial side of the economy unaffected. Of course, this statement applies only at the steady-state. Transitionally, as shown by Carlstrom and Fuerst (2001), the markup rises and dampens the initial impact of the policy. This is so because employment rises but net worth cannot jump so that firms react by paying the risen input bill with additional debt and by contracting with banks at higher $\bar{\omega}$. In the long-run, equity adjusts and the debt ratio converges towards its initial steady-state position since economic fundamentals remain unchanged.

Next, consider a unilateral change of the nominal interest on loans by one percentage point. Such a policy remained unexplored by Carlstrom and Fuerst (2001) and the related agency-cost 
literature because the modelling did not include a risk-independent cost of debt and an explicit banking sector. Taking these into account, the present model predicts quite strong real effects of the policy, shown in the fourth row of the final panel of Table 2. The generally lower cost of debt causes the mark-up on factor costs to fall, which in turn leads to more efficient use of factors and higher employment. The calibration predict a 0.9 percent increase of aggregate production and a 0.5 percent increase of productivity.

Summarizing, we observe efficiency gains from a cut of the nominal interest rate on deposits originating from the factor supply side and from a cut of the nominal interest rate on loans originating from the factor demand side. The banking equilibrium combines both effects. Inspection of Table 2 shows that the combined effect is approximately the sum of the individual effects. It can also be seen that a limited focus on just the deposit channel would underestimate the whole effect by more than half of its magnitude and would not perceive any adjustment on the financial side of the economy.

Finally, we inspect policy changes for the reserve ratio. Results compiled in the final two rows of Table 2 suggest only very small effects from quite drastic changes of the reserve ratio (from 0.05 up to 0.10 and down to zero). This finding may serve two purposes. First, it verifies robustness of the calibration with respect to alternative assumptions about the actual reserve ratio. Secondly, it can be exploited to shed light on the empirical controversy about the credit channel. Since a changing reserve ratio directly affects credit supply, the policy utilizes the bank lending channel or the credit channel in its strict sense. The small reactions predicted by the model are in line with the empirical literature, which usually fails to find strong effects through this type of the credit channel. Now compare with an interest rate policy. To really make the point we could set the reserve ratio to zero, and consider any financial intermediary that costly transforms deposits into loans. Evidence for such a broadly understood credit channel is much more supportive (see e.g. Walsh, 2003, Chapter 7). A change of the nominal interest rate on deposits has - besides the usually explored adjustments through household asset and time allocation - also an impact on corporate finance and factor use. The present model predicts that real effects through this type of lending channel are quite strong. In an attempt to reconcile views it may be called the interest-rate-driven credit channel. 


\section{Monetary Policy and the Business Cycle}

While the analysis so far has been focussed on long-run effects, the model can also be applied to reconsider the financial accelerator in the real business cycle literature. Following this literature we now introduce the monetary policy rule (14) and assume as Carlstrom and Fuerst (and many others) that $\rho=0.9$ and $\epsilon_{t}^{i}=-0.01$ at $t=0$ and zero otherwise. The basic idea of the financial accelerator is that higher production and sales after a positive shock increases next period's net worth such that firms demand more debt. This enables them to run a higher input bill, employ more factors, and produce more output then they would if they were completely equity financed.

Figure 2. The Credit Channel without Banking Sector
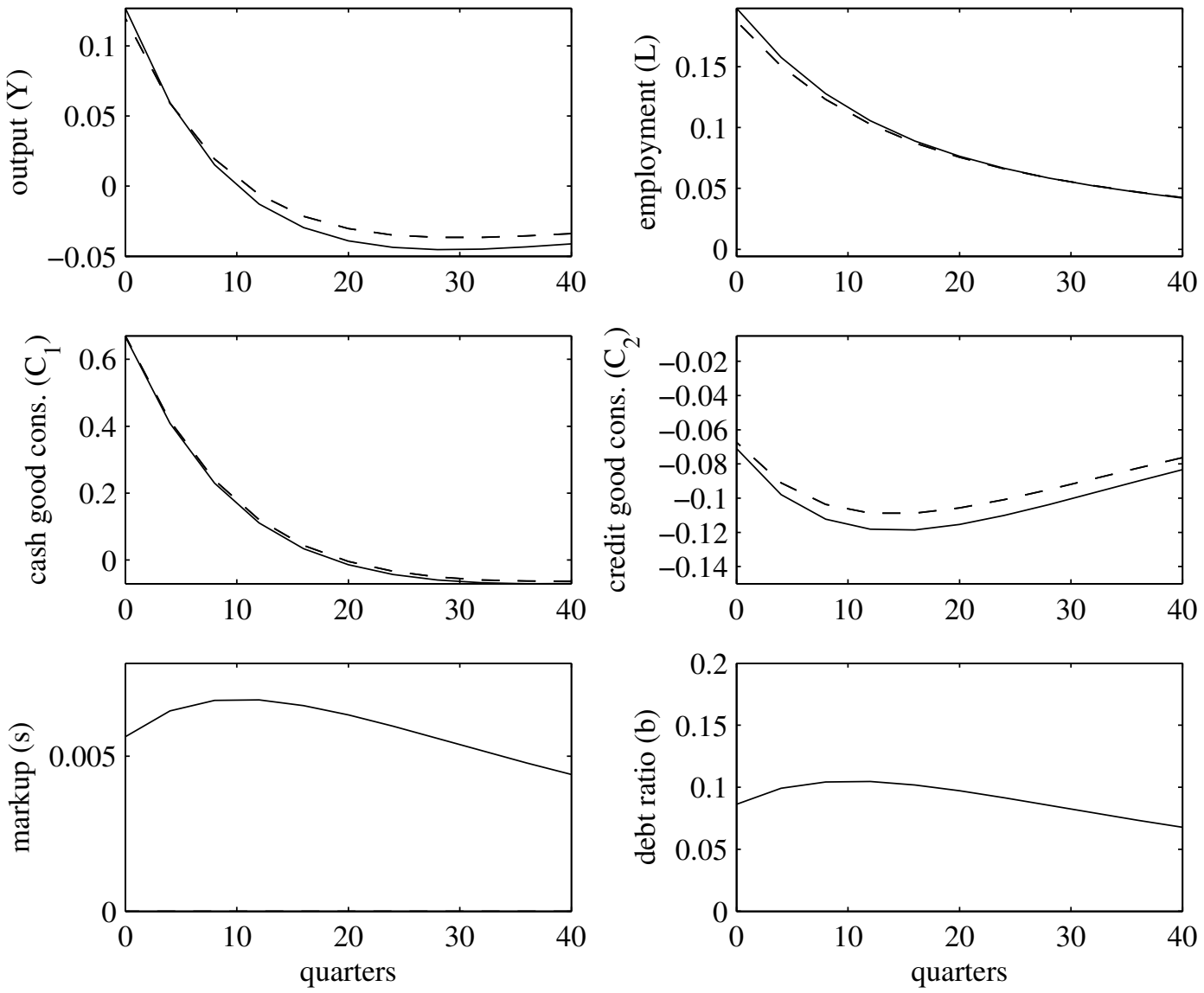

The central bank follows an interest rate rule $\hat{i}_{t+1}=\rho \hat{i}_{t}+\epsilon_{t}^{i}$ with $\epsilon_{t}^{i}=-0.01$, i.e. a one percentage point decrease at $t=0$, and zero otherwise. $\hat{i}$ is the log deviation of the nominal interest rate on deposits. Solid lines show impulse responses for the model with credit channel (but disabled banking sector). Dashed lines show results for the standard model (without credit channel).

Disappointingly though, Carlstrom and Fuerst (2001) have not found that the financial acceler- 
ator adds much amplification and propagation to monetary policy shocks in the version of their model that comes closest to the present one. They then proceed by assuming that only investment is debt financed and by adding a wealth shock. Here, were are not pursuing these ideas but instead consider amplification through the banking system. An explicitly modelled banking sector (as well as a corporate sector) was not present in Carlstrom and Fuerst's analysis and comparative steadystate analysis has already shown for the present model that changes of the nominal interest rate are amplified through the banking system. This lets us expect amplification of temporary shocks as well.

To begin with, we again consider a unilateral change of $i^{D}$ as specified by the policy rule and ignore the association with $i^{L}$ through banking equilibrium, i.e. we keep $i^{L}$ constant. This experiment comes closest to Carlstrom and Fuerst's analysis assumption that the financial intermediary charges no interest beyond the risk premium (i.e. $i^{L}$ is kept constant at zero for all times). Employing the backward integration method I use the fact that aggregate capital cannot jump and find the unique adjustment as the trajectory that originates and ends at $K^{*}$ and fulfils (19) and (20) and the monetary policy rule (14). Results are shown in Figure 2.

Adjustment dynamics are shown by solid lines for the present model and by dashed lines for an otherwise identical model without financial intermediation, i.e. a Cooley and Hansen (1992) type of model with completely equity financed firms. The two main insights from Figure 2 are that financial intermediation does not change impulse responses of aggregate output and of employment very much and that the markup rises as a response to the monetary innovation. These results resemble qualitatively the findings by Carlstrom and Fuerst. ${ }^{4}$ After the initial interest rate cut household react by supplying more factors and firms react by running higher input bills. But net worth is given initially so that firms finance a larger part of factor costs through credit and contract with banks at higher $\bar{\omega}$, which results in higher markups on factor costs. This process is indeed very persistent since net worth is only slowly accumulated. The largest markup is reached about ten quarters after the monetary innovation. Quantitatively, however, the effect of access to credit is very small. With access to credit, firms employ a little more labor at the expense of generally lower productivity. The financial accelerator does not accelerate much.

Now consider the full model with interaction through banking equilibrium (1). Adjustment dynamics are shown in Figure 3. The monetary innovation $i^{D}$ and the resulting time series for the

${ }^{4}$ Carlstrom and Fuerst find a somewhat stronger impact because they assign a larger role to debt finance and because they consider entrepreneurs who differ from ordinary households, i.e. the stockholders of firms in the present model. 
Figure 3. The Credit Channel with Banking Sector
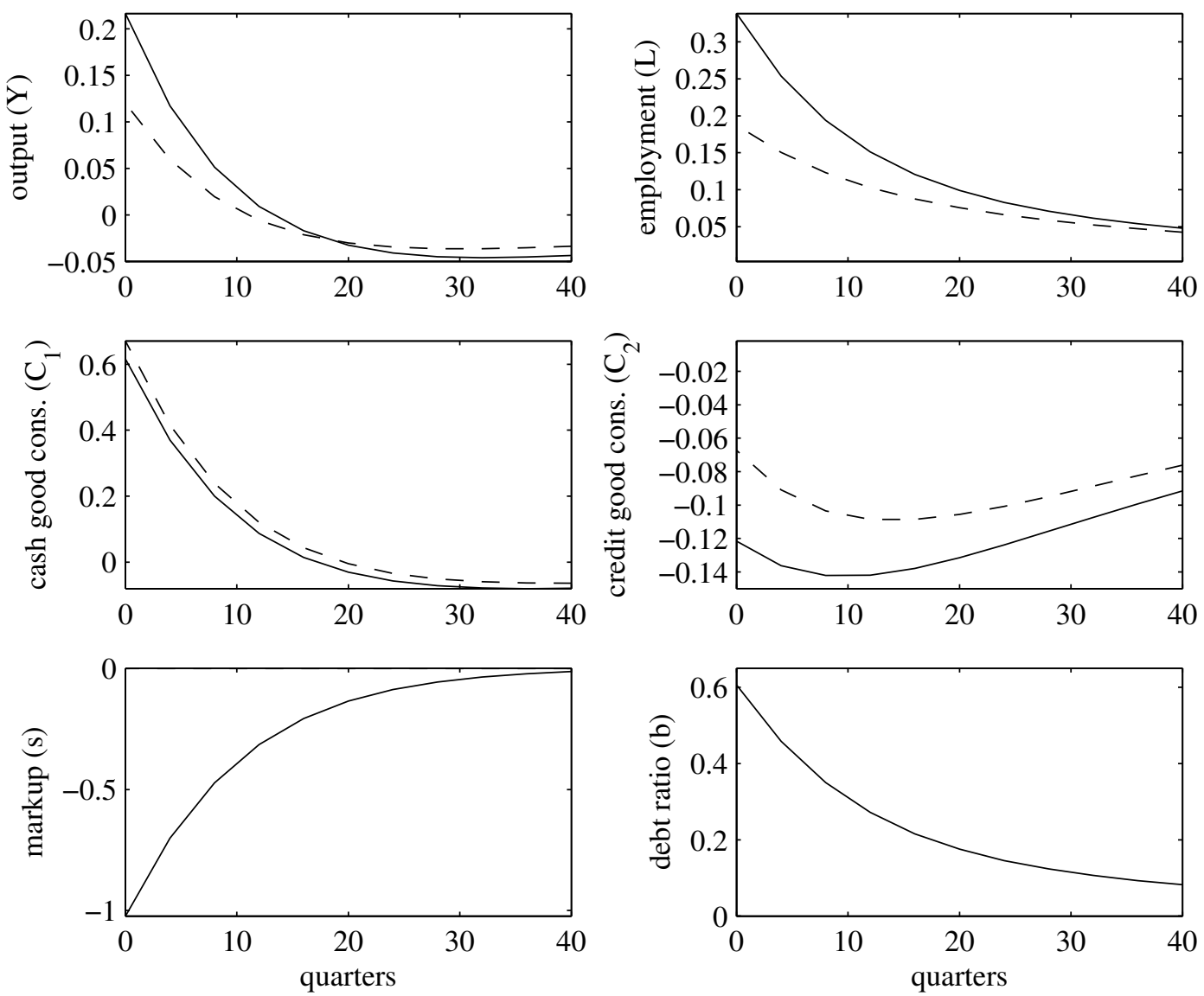

As for Figure 1, the central bank follows an interest rate rule $\hat{i}_{t+1}=\rho \hat{i}_{t}+\epsilon_{t}^{i}$ with $\epsilon_{t}^{i}=-0.01$ at $t=0$ and zero otherwise. $\hat{i}$ is the log deviation of the nominal interest rate on deposits. Solid lines show impulse responses for the model with credit channel and enabled banking sector. Dashed lines show results for the standard model (without credit channel).

deposit rate is translated into a proportional time series for the lending rate $i^{L}$. As a consequence, firms can now employ the increasing factor supply at lower costs of debt. The positive effect of generally lower lending rates is clearly dominating the negative effect of the somewhat higher risk of bankruptcy. The markup drops by one percentage point initially, (from 1.10 to 1.09) and is below steady-state level over the whole adjustment path. This allows firms to expand much more than under the previous scenario. Initially the debt ratio increases by 0.6 percentage points from 19.4 to 2.00. Impulse responses of both output and employment are almost twice as large as in the case of completely equity financed firms. The financial accelerator lives up to his name. 


\section{Conclusion}

This paper has integrated two views on the credit channel: the monetary economics view emphasizing agency costs of debt and the public economics view emphasizing tax benefits of debt. The resulting unifying theory has provided an institutionally based explanation of financial structure. Such micro-founded financial structure has been integrated into a neoclassical growth framework together with an explicitly modelled banking sector that eliminates idiosyncratic risk and channels households' funds to firms.

The interplay between costly banking, monetary policy, and fiscal policy has lead to a reassessment of the financial accelerator. Because the banking system is translating borrowing rates into lending rates, a policy innovation that leads to adjustment through the "ordinary" savings channel entails also an adjustment through the credit channel. A cut of the interest rate on deposits, for example, is translated into a cut of the interest rate on loans, which allows firms to contract with banks at lower costs and to operate larger projects, implying, on the aggregate, higher employment of capital and labor.

A calibration with US data finds that the refined theory modifies previous estimates of effects of fiscal policy not tremendously. With respect to monetary policy, however, the combined effects through the savings channel and the credit channel are much stronger than inferred from the earlier literature (i.e. when costly banking is neglected). This is true for the long-run impact of permanent policy changes as well as for the short run impulse responses to temporary policy changes. 


\section{APPENDIX}

Firms. The Lagrangian for maximizing (7) subject to (8) reads

$$
L=\sum_{t=0}^{\infty} \beta^{t}\left\{D_{t}+q_{t}\left[\left(1-\tau_{r}\right)\left\{\left[\chi_{t} \cdot\left(1+r_{t}-\delta\right)-1\right] K_{t}^{E}-D_{t}\right\}+K_{t}^{E}-K_{t+1}^{E}\right]\right\}
$$

with $\beta^{t} \equiv \prod_{j=0}^{t}\left[1+\left(1-\tau_{p}\right)\left(r_{j}-\delta\right)\right]^{-j}$. The first order conditions are

$$
\begin{aligned}
& 1-q_{t}\left(1-\tau_{r}\right)=0 \\
& \beta^{t+1} q_{t+1}\left\{\left(1-\tau_{r}\right)\left[\chi_{t+1}\left(1+r_{t+1}-\delta\right)-1\right]+1\right\}-\beta^{t} q_{t}=0 .
\end{aligned}
$$

From (A.3) $q_{t+1}=q_{t}$ for all $t$. Insert this information and (A.3) into (A.4) to get

$$
\beta\left[\chi_{t}\left(1+r_{t}-\delta\right)-1\right]+\frac{\beta}{1-\tau_{r}}=\frac{1}{1-\tau_{r}} \quad \Rightarrow \frac{1}{\beta}=\left(1-\tau_{r}\right)\left[\chi_{t}\left(1+r_{t}-\delta\right)-\right]+1 .
$$

Insert the definition of $\beta$ to arrive at (9) in the text.

Evaluating firm value (7) at two different periods provides the no-arbitrage condition

$$
D=\left(1-\tau_{p}\right)\left(r_{t}-\delta\right) V_{t}
$$

Households. Inserting the no-arbitrage condition (A.5) the budget constraint (11) becomes

$W_{t+1}+\frac{d_{t+1}}{p_{t}}+\frac{M_{t+1}}{p_{t}}=\left(1-\tau_{w}\right) w_{t} L_{t}+\left[1+\left(1-\tau_{p}\right)\left(r_{t}-\delta\right)\right] W_{t}+\left[1+\left(1-\tau_{p}\right) i_{t}^{D}\right] \frac{d_{t}}{p_{t}}+T+\frac{M_{t}}{p_{t}}-C_{1, t}-C_{2, t}$

with $W_{t} \equiv K_{t}^{H}+V_{t}$. The Lagrangian for maximizing (10) with respect to (A.6) and the CIA condition reads

$$
\begin{aligned}
& L=\sum_{t=0}^{\infty} \beta^{t}\left[U\left(C_{1, t}, C_{2, t}, 1-L_{t}\right)+\mu_{t}\left\{C_{1, t}-\frac{M_{t}}{p_{t}}\right\}\right. \\
& \left.+\lambda_{t}\left\{\left(1-\tau_{w}\right) w_{t} L_{t}+\left[1+\left(1-\tau_{p}\right)\left(r_{t}-\delta\right)\right] W_{t}+\left[1+\left(1-\tau_{p}\right) i_{t}^{D}\right] \frac{d_{t}}{p_{t}}+T+\frac{M_{t}}{p_{t}}-C_{1, t}-C_{2, t}-W_{t+1}-\frac{d_{t+1}}{p_{t}}-\frac{M_{t+1}}{p_{t}}\right\}\right]
\end{aligned}
$$

The first order conditions for the control variables $C_{1, t}, C_{2, t}, L_{t}, W_{t+1}, d_{t+1}$, and $M_{t+1}$ are as follows.

$$
\begin{aligned}
& U_{c}\left(C_{1, t}\right)-\lambda_{t}+\mu_{t}=0 \\
& U_{c}\left(C_{2, t}\right)-\lambda_{t}=0 \\
& U_{L}+\lambda_{t}\left(1-\tau_{w}\right) w_{t}=0 \\
& \beta \lambda_{t+1}\left[1+\left(1-\tau_{p}\right)\left(r_{t+1}-\delta\right)\right]-\lambda_{t}=0 \\
& \beta \lambda_{t+1}\left[1+\left(1-\tau_{p}\right) i_{t+1}^{D}-\delta\right] \frac{1}{p_{t+1}}-\frac{\lambda_{t}}{p_{t} 0}=0 \\
& \beta \frac{\lambda_{t+1}}{p_{t}}-\frac{\lambda_{t}}{p_{t}}-\beta \frac{u_{t+1}}{p_{t+1}}
\end{aligned}
$$

From (A.7)

$$
\lambda_{t+1}-\mu_{t+1}=U_{c}\left(C_{1, t+1}\right) .
$$

Insert this into (A.12)

to get

$$
\beta\left[\lambda_{t+1}-\mu_{t+1}\right] \frac{p_{t}}{p_{t+1}}=\lambda_{t}
$$

$$
\lambda_{t}=\beta U_{c}\left(C_{1, t+1}\right) \frac{p_{t}}{p_{t+1}}
$$


From (A.11)

$$
\lambda_{t}=\beta \lambda_{t+1}\left[1+\left(1-\tau_{p}\right) i_{t+1}^{D}\right] \frac{p_{t}}{p_{t+1}} .
$$

Substitute $\lambda$ from (A.13) to arrive at

$$
\lambda_{t+1}\left[1+\left(1-\tau_{p}\right) i_{t+1}^{D}\right]=U_{c}\left(C_{1, t+1}\right) \quad \Rightarrow \quad \lambda_{t}\left[1+\left(1-\tau_{p}\right) i_{t}^{D}\right]=U_{c}\left(C_{1, t}\right) .
$$

Insert (A.8) to get (12b) in the text. From (A.10)

$$
\beta\left[1+\left(1-\tau_{p}\right)\left(r_{t+1}-\delta\right)\right]=\frac{\lambda_{t}}{\lambda_{t+1}} .
$$

Insert (A.8) to get (12a) in the text. Insert (A.14) to get (13) in the text. Finally, insert (A.8) into (A.8) to get $(12 \mathrm{c})$ in the text.

Lemma 1. Recall from the debt contract that

$$
f^{\prime}\left(\bar{\omega}_{t}(i)\right)=\Phi\left(\bar{\omega}_{t}(i)\right)-1<0 \quad \Rightarrow \quad f^{\prime \prime}\left(\bar{\omega}_{t}(i)\right)=\phi\left(\bar{\omega}_{t}(i)\right)>0 .
$$

Differentiate (5) implicitly and obtain that $\partial \bar{\omega}_{t} / \partial s_{t}>0$ requires $\phi^{\prime} f^{\prime}-\phi f^{\prime \prime}<0$. Insert (A.15) and write this condition as $(1-\Phi) \phi^{\prime}+\phi^{2}>0$, which is fulfilled because the hazard rate is increasing in $\bar{\omega}$ (Assumption 1). Thus default values and mark-ups are positively correlated.

With the notion of an implicit function $\bar{\omega}\left(s_{t}\right), \chi_{t}$ in (6) can be understood as a function of $s_{t}$. Compute the derivative $\partial \chi_{t} / \partial s_{t}=\left[\left(1+i_{t}^{L}\right)\left(f^{\prime} \bar{\omega}^{\prime} s_{t}+f\right)\left(1+i_{t}^{L}-s g\right)+\left(1+i_{t}^{L}\right) f s_{t}\left(g^{\prime} \bar{\omega}^{\prime} s_{t}+g\right)\right] /\left(1-s_{t} g\right)^{2}$. Use (4) to replace $g$ and $g^{\prime}$ and substitute $s$ from (7) to see that the numerator of this expression simplifies to $f\left(\bar{\omega}_{t}\right)>0$. Thus the correlation between internal rate of return and mark-up is positive, $\partial \chi_{t}\left(s_{t}, \bar{\omega}\left(s_{t}\right)\right) / \partial s_{t}>0$.

By the chain rule, $\partial s_{t} / \partial r_{t}=\left(\partial \chi_{t} / \partial r_{t}\right) /\left(\partial \chi_{t} / \partial s_{t}\right)$. Obtain $\partial \chi_{t} / \partial r_{t}>0$ from (9) and Assumption 2. Thus the numerator on the right hand side is positive. It has just been shown that the denominator is positive as well. Thus the correlation between interest rate and mark-up is positive (for any given set of taxes $\left(\tau_{r}, \tau_{p}, \tau_{c}, z\right)$ fulfilling Assumption 2)

Apply the implicit function theorem on (3), i.e. on $F_{K t}-s_{t} r_{t}=0$ and use $F_{K K t}<0$ and the result from above that $\partial s_{t} / \partial r_{t}>0$ to conclude that the correlation between capital stock and interest rate is negative for any given set of taxes $\left(\tau_{r}, \tau_{p}, \tau_{c}, z\right)$ fulfilling Assumption 2 .

Lemma 2. Evaluate (6) at the steady-state as an implicit function of $\bar{\omega}$ and $1+i^{L}$.

$$
G\left(\bar{\omega}, 1+i^{L}\right)=\frac{s_{t} \cdot f\left(\bar{\omega}_{t}(i)\right)}{\left(1+i_{t}^{L}\right)-s_{t} \cdot g\left(\bar{\omega}_{t}(i)\right)}-\chi^{*} .
$$

Obtain $\partial G / \partial\left(1+i^{L}\right)=-s f / N^{2}<0$, with $N \equiv 1+i^{L}-s g$. Compute

$$
\frac{\partial G}{\partial \bar{\omega}}=\frac{1}{N^{2}}\left\{\left(1+i^{L}\right)\left[s f^{\prime}+f s^{\prime}\right]-s^{2}\left[g f^{\prime}-f g^{\prime}\right]\right\}=\frac{1}{N^{2}}\left\{\left(1+i^{L}\right)\left[s f^{\prime}+f s^{\prime}\right]-s^{2} f^{\prime}\left[1-\mu \Phi+\mu \phi f / f^{\prime}\right]\right\}
$$

where the second equality on the right is obtained after inserting $g$ from (4). Now recall the definition of $s$ to see that $\left[1-\mu \Phi+\mu \phi f / f^{\prime}\right]=\left(1+i^{L}\right) / s$ implying that the whole expression collapses to

$$
\frac{\partial G}{\partial \bar{\omega}}=\frac{1}{N^{2}} f s^{\prime}>0,
$$

since $s^{\prime}>0$ from Lemma 1 . Applying the implicit function theorem we thus obtain $\partial \bar{\omega} / \partial\left(1+i^{L}\right)>0$, which proves Lemma 2 .

Stability analysis. For analysis of global stability, conclude from (20) that the isocline where $\Delta c_{2, t} \equiv$ $c_{2, t+1}-c_{2, t}=0$ is given by the horizontal curve

$$
r\left(k^{*}\right)=\left[\frac{(1+\gamma)^{\sigma}}{\beta}-1\right] /\left(1-\tau_{p}\right)+\delta
$$


Use Lemma 1 to conclude that from $k>k^{*}$ follows $r<r^{*}$ and thus $\Delta c_{2, t}<0$. Thus, in the phase diagram of Figure 2 the arrows of motion point towards smaller $c_{2, t}$ to the right of $k^{*}$ and - analogously - the arrows of motion point towards larger $c_{2, t}$ to the left of $k^{*}$.

The $\Delta k_{t}=0$-isocline is computed from (19) as

$$
c_{2, t}=\frac{f\left(k_{t}\right)\left[1-\mu \phi\left(\bar{\omega}_{t}\right)\right]\left(1-g_{s}\right)-\delta k_{t}}{a}
$$

with $a \equiv 1+\left\{1+\eta\left[1+\left(1-\tau_{p}\right) i^{D}\right]\right\}^{-1} /(1-\eta)>1$, a constant positive value. The slope is

$$
\frac{\partial c_{2, t}}{\partial k_{t}}=\frac{1}{a}\left\{f^{\prime}\left(k_{t}\right)\left[1-\mu \Phi\left(\bar{\omega}_{t}\right)\right]-f\left(k_{t}\right) \mu \phi\left(\bar{\omega}_{t}\right) \cdot \frac{\partial \bar{\omega}_{t}}{\partial k_{t}}\right\}\left(1-g_{s}\right)-\delta
$$

Use the fact that $\partial \bar{\omega} / \partial k<0$ from Lemma 1. Thus $\Phi(\bar{\omega})$ approaches one for $k \rightarrow 0$ and zero for $k \rightarrow \infty$. Since it follows from the Inada conditions that $f^{\prime}(k)$ approaches zero for $k \rightarrow \infty$ and $f^{\prime}(k)$ approaches infinity for $k \rightarrow 0$, the $\Delta k_{t}=0$-curve rises with infinite slope from the origin, reaches a finite maximum and falls to zero at finite $k_{t}$ as shown in Figure 2. Below the curve consumption is less than the value that supports $\Delta k_{t}=0$ and thus the arrows of motion point towards larger $k_{t}$. Analogously, the arrows of motion point towards smaller $k_{t}$ above the $\Delta k_{t}=0$-curve. From the arrows of motion shown for the complete phase diagram in Figure 4 we conclude that the equilibrium at the intersection of both curves is globally saddlepoint-stable. The unique solution that fulfils the first order conditions (and the corresponding transversality condition) for the households' consumption maximization problem, i.e. the policy function $c_{2, t}\left(k_{t}\right)$, is given by a (discrete) movement along the stable manifold towards the equilibrium.

Figure 4. Phase Diagram

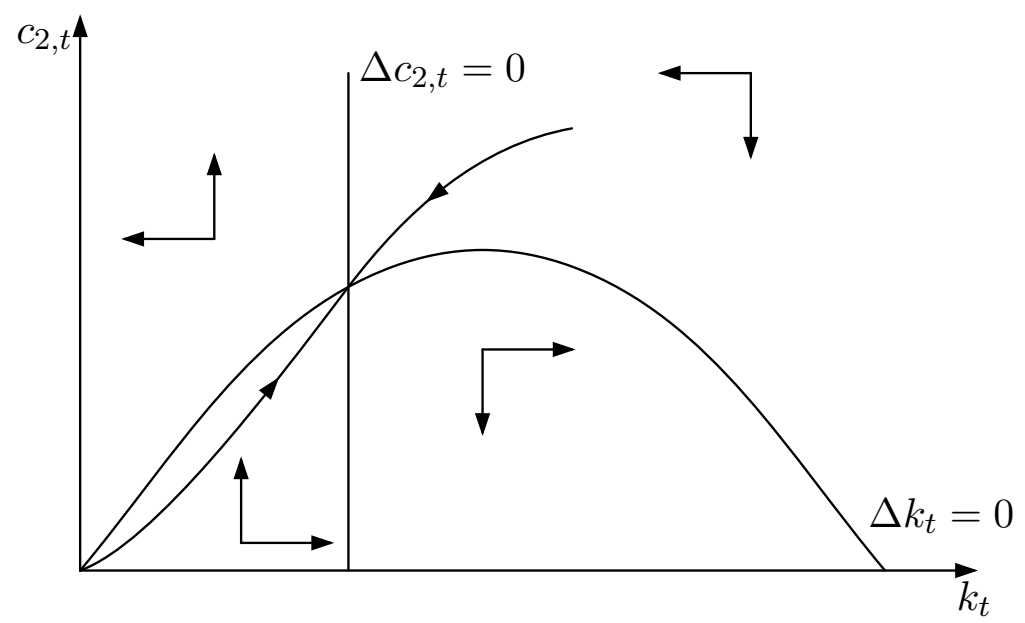




\section{References}

Auerbach, A.C., 2002, Taxation and corporate financial policy, in: A.C. Auerbach and M. Feldstein, eds. Handbook of Public Economics Vol. 3, North Holland, Amsterdam, 1251-1292.

Barro, R.J. and X. Sala-i-Martin, 2004, Economic Growth, 2nd ed., MIT Press, Cambridge, MA.

Bernanke, B. and M. Gertler, 1989, Agency costs, net worth and business fluctuations, American Economic Review, 79, 14-31.

Bernanke, B. and M. Gertler, 1995, Inside the black box: The credit channel of monetary policy transmission, Journal of Economic Perspectives 9, 27-48.

Brunner, M. and H. Strulik, 2002, Solution of perfect foresight saddlepoint problems: A simple method and applications, Journal of Economic Dynamics and Control 26, 737-753.

Brunner, M. and H. Strulik, 2004, A Simple and intuitive method to solve small rational expectations models, Journal of Economics 82, 71-88.

Carey, D., and H. Tchilinguirian, 2000, Average effective tax rates on capital, labour, and consumption, OECD Working Paper No. 258

Carlstrom, C.T. and T.S. Fuerst, 1997, Agency costs, net worth and business fluctuations: A computable general equilibrium analysis, American Economic Review, 87, 893-910.

Carlstrom, C.T. and T.S. Fuerst, 2001, Monetary shocks, agency costs, and business cycles, Carnegie Rochester Conference Series on Public Policy 54, 1-27.

Chari, V.V., L.E. Jones, and R.E. Manuelli, 1996, Inflation, growth, and financial intermediation, Federal Reserve Bank of Minneapolis Quarterly Review 19, 18-32.

Cooley, T.F. and V. Hansen, 1989, The inflation tax in a real business cycle model, American Economic Review 79, 733-748.

Cooley, T.F. and V. Hansen, 1992, Tax distortions in a neoclassical monetary economy, Journal of Economic Theory 58, 290-316.

Cooley, T.F. and V. Quadrini, 2006, Monetary policy and the financial decisions of firms, Economic Theory 27, 243-270.

Diaz-Gimenez, J., E.C. Prescott, T. Fitzgerald, and F. Alvarez, 1992, Banking in computable general equilibrium economies, Journal of Economic Dynamics and Control 16, 533-559.

Gavin, W.T., F.E. Kydland, and M.R. Pakko, 2007, Monetary policy, taxes, and the business cycle, Journal of Monetary Economics 54, 1587-1611.

Gordon, R.H and Y. Lee, 2001, Do taxes affect corporate debt policy? Evidence form U.S. corporate tax return data, Journal of Public Economics 82, 195-224.

Gordon, R.H and Y. Lee, 2007, Interest rates, taxes and corporate financial policies, National Tax Journal, 65-84.

Graham, J.R., 2000, How big are the tax benefits of debt?, Journal of Finance 55(5), 1901-1941. 
Graham, J. R., 2006, Taxes and corporate finance, in: B. E. Eckbo (ed.): Handbook of Corporate Finance Empirical Corporate Finance, Amsterdam: Elsevier Science.

Lucas, R.E., Jr., 1990, Supply-side economics, an analytical review, Oxford Economic Papers 42, 293-316.

OECD, 1991, Taxing profits in a global economy: Domestic and international issues, Paris.

Osterberg, W.P., 1989, Tobin's q, investment, and the endogenous adjustment of financial structure, Journal of Public Economics 40, 293-318.

Sinn, H.W., 1987, Capital Income Taxation and Resource Allocation, Amsterdam, North-Holland.

Strulik, H., 2003, Capital tax reform, corporate finance, and economic growth and welfare, Journal of Economic Dynamics and Control 28, 595-615.

Strulik, H., 2008, The credit channel of capital tax policy, Journal of Public Economic Theory, forthcoming.

Townsend, R.M., 1979, Optimal contracts and competitive markets with costly state verification, Journal of Economic Theory.

Turnovsky, S.J., 1990, The effects of taxes and dividend policy on capital accumulation and macroeconomic behavior, Journal of Economic Dynamics and Control 14, 491-521.

Walsh, C.E., 2003, Monetary Theory and Policy, 2nd ed., MIT Press, Cambrdige, MA. 